\title{
Evaluation of Ion-pair Formation of Adefovir to Improve Permeation across Artificial and Biological Membranes
}

\author{
Bahar Darsazan $^{1}$, Alireza Shafaati ${ }^{2},{\text { Afshin } \text { Zarghi }^{2}, \text { Seyed Alireza Mortazavi }}^{1}$ \\ 1. Department of Pharmaceutics, and 2. Department of Pharmaceutical Chemistry School of Pharmacy, Shahid Beheshti \\ University of Medical Sciences, Tehran, Iran.
}

Received, January 1, 2018; Revised, February 4, 2018; Accepted, May 9, 2018; Published, May 10, 2018.

\begin{abstract}
Purpose: Adefovir is an antiviral drug that exhibits high hydrophilic properties and negligible bioavailability (less than 12\%). It is only applied in the form of the ester prodrug adefovir dipivoxil (ADV). The oral bioavailability of ADV is limited (32\% to $45 \%$ ) by its low permeability (Class 3 ) and biological conversion of the prodrug to adefovir. Ion-pair formation is considered as an alternative approach to a covalent prodrug (ADV) to enhance intestinal permeation of adefovir. Methods: The effect of various counter-ions (anionic, cationic and two quaternary ammonium salts) on the lipophilicity of adefovir was investigated by means of the $\mathrm{n}$-octanol/buffer partitioning system, an in vitro transport model (PAMPA) and a biological membrane (everted gut sac). Results: Quaternary ammonium salts, cetylpyridinium chloride (CPC) and cetrimide enhanced the lipophilicity of adefovir 136- and 87-fold, respectively. The apparent permeability of adefovir in combination with CPC (counter-ion) was 2.5 -fold greater than ADV permeability in the PAMPA model. The apparent permeability of adefovir-CPC (counter-ion) was 1.3 -fold greater than that of adefovir dipivoxil permeability in a biologic membrane (everted gut sac). Conclusion: These results suggest that the adefovir-CPC ion-paired system has potential for improving the permeation of adefovir across the intestinal membrane.
\end{abstract}

This article is open to POST-PUBLICATION REVIEW. Registered readers (see "For Readers") may comment by clicking on ABSTRACT on the issue's contents page.

\section{INTRODUCTION}

Certain classes of antiviral drugs tend to be polar, therefore; they may show poor intestinal permeation and insufficient oral absorption. Among these drugs is adefovir (9-[2-phosphonomethoxy) ethyl] adenine), an acyclic nucleotide analogue reverse transcriptase inhibitor (Figure 1) used for the treatment of chronic hepatitis B virus $(1,2)$ and herpes simplex infection (3).

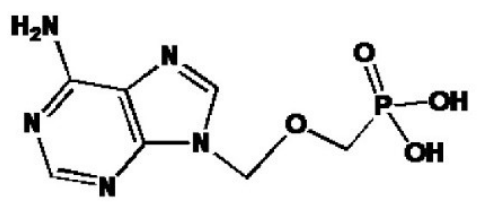

Figure 1. Chemical structure of adefovir.

There are now three drugs licensed in Europe, North America and parts of Asia for chronic hepatitis B: IFN- $\alpha$, lamivudine and adefovir (4). Adefovir is preferred over lamivudine because the $\mathrm{HB}$ virus develops resistance to it over a longer period of time (4). IFN- $\alpha$ is of limited use in patients with decompensated cirrhosis, patients with HIV co-infection and immunosuppressed patients (4). Adefovir is a highly polar and extraordinarily hydrophilic antiviral drug that lacks sufficient intestinal permeability (5). It is formulated as a pivoxil prodrug, adefovir dipivoxil (ADV). The oral bioavailability of ADV appears to be limited also by its biological conversion of the prodrug to adefovir and the low permeability of adefovir (5). Ester prodrugs are extremely prone to being hydrolyzed during oral absorption. Pre-systematic metabolism often leads to poor drug bioavailability (6). On the basis of the FDA guidelines for immediate-release solid oral dosage forms, ADV can be classified as a high solubility/low permeability drug (Class 3) (5).

Corresponding Authors: This paper has two corresponding authors (Seyed Alireza Mortazavi, mortazavisar@yahoo.com and Afshin zarghi,ZZarghi@sbmu.ac.ir_No. 2660, Vali-e-asr Ave, Tehran, Iran. 
The intestinal permeation of adefovir dipivoxil is passively and prodrug is metabolized to parent drug (adefovir) in the enterocytes during intestinal absorption. Basolateral efflux of adefovir assist the absorption of drug when adefovir dipivoxil was dosed on the apical side $(7,8)$.

Various strategies exist to improve oral drug absorption, including preparation of prodrugs and drug conjugates, and formulation strategies such as improving the drug solubility and dissolution rate, formulation with permeation enhancers and coadministration with delivery agents (ion-pairing) (9). An analogous strategy to the covalent prodrug approach is the non-covalent ion-pairing approach, wherein a highly charged, polar molecule with poor membrane permeability is coupled with a lipophilic counter-ion of equal and opposite charge to form an ion-pair in solution that is able to passively permeate the cell membrane (10). The ion-pair in solution is absorbed and then readily dissociates after absorption through dilution in the blood stream. The ion-pairing approach for increasing oral absorption has several advantages. It is fundamentally easy and excludes the need for prodrug uptake by transporters and activation by specific enzymes $(10,11)$. As opposed to prodrugs, the ion-pair strategy does not require chemical modification of the drug or creation of new chemical entities and this is a considerable advantage in term of reduced cost and development time (9). Adefovir ion-pair crosses of the apical side of enterocytes by passive diffusion like adefovir dipivoxil, as ion-pairing is a non-covalent approach, in both methods we have parent drug (adefovir) in the enterocytes that can be egressed by basolateral efflux into the circulation system and present of basolateral efflux transporter is not in conflict of the permeability of the ion-pair because in both method, we have passive diffusion in apical side (7, 8).

Ion-pairing of a hydrophilic drug with an appropriate counter-ion in order to improve its permeability and bioavailability has been well established mainly by the research activity of Neubert et al. $(12,13)$.

Mrestani et al. significantly improved the oral absorption of cefpirome using the cationic ionpairing agent hexadecyl dimethyl benzyl ammonium chloride and the anionic ion-pairing agent hexylsalicylic acid (HSA) in rabbits (14). Various investigators have successfully used the ion-pairing approach to increase oral absorption (10, 15-20).

The aim of this work was to enhance intestinal absorption of the low-permeability antiviral agent adefovir by ion-pairing as an alternative to the prodrug, ADV. To the best of our knowledge, no previous work has been reported in the literature on this subject. The approach involved determination of the apparent octanol-buffer ( $\mathrm{pH}$ 6.5) distribution coefficients (D) and apparent membrane permeability $\left(\mathrm{P}_{\text {app }}\right)$ in the parallel artificial membrane permeation assay (PAMPA) and everted gut sac in the presence of selected counter-ions. The counter-ions studied in this work include different acidic, basic and quaternary ammonium compounds with varying amounts of lipophilicity, chemical structures and functional groups.

\section{MATERIALS AND METHODS}

Adefovir and ADV were obtained from Zhejiang Charioteer Pharmaceutical (China) and lecithin was purchased from Sigma (Germany). Cetylpyridinium chloride (CPC) and all other reagents and chemicals were obtained from Merck (Germany). Hydrophobic microfilter membranes (polyvinylidene fluoride; PVDF; $0.45 \mathrm{~mm}$ ) as the donor compartment and acceptor plates for the PAMPA experiments were purchased from Millipore (USA).

\section{High performance liquid chromatography (HPLC)}

Both adefovir and ADV were determined by the RP-HPLC. The method of ADV is described completely elsewhere (21). For both methods, the HPLC (Kanuer Smartline; Germany) comprised of an EA4300F pump and E4310 2500 UV-visible detector. Samples $(40 \mu \mathrm{l})$ were injected by means of a Rheodyne injector fitted with a $20-\mu 1$ loop. The instrumentation was controlled using EZchrom Elite software. The compounds were separated on a Nucleodur column (Machery-Naghel; Germany) with $\mathrm{C}_{18}$ packing $5-\mu \mathrm{m}$ particle size and L x I.D. 15 $\mathrm{cm} \times 4.6 \mathrm{~mm}$. The eluate was monitored at $260 \mathrm{~nm}$. The mobile phase was freshly prepared each day and filtered through a $0.45-\mu \mathrm{m}$ membrane filter. The chromatographic separation of ADV was performed using a mixture of acetonitrile-citrate buffer (10 $\mathrm{mM}$ at $\mathrm{pH} 5.2) 36: 64(\% \mathrm{v} / \mathrm{v})$ as mobile phase, at a flow rate of $1.5 \mathrm{~mL} / \mathrm{min}$. A sharp peak was obtained for ADV at a retention time of $5.8 \pm$ 
$0.01 \mathrm{~min}$. The method was validated according to the international guidelines. Linear regression analysis of data for the calibration plot showed a linear relationship between peak area and concentration over the range of $0.5-16 \mu \mathrm{g} / \mathrm{mL}$; the regression coefficient was 0.9999 and the linear regression equation was $y=24844 x-2941.3$. The detection (LOD) and quantification (LOQ) limits were 0.12 and $0.35 \mu \mathrm{g} / \mathrm{mL}$, respectively.

Another simple and reliable RP-HPLC method was developed and validated for analysis of adefovir. The chromatographic separation was performed using a mixture of methanol-citrate buffer (10 $\mathrm{mM}$ at $\mathrm{pH} 5.2) 12: 88(\% \mathrm{v} / \mathrm{v})$ as mobile phase, at a flow rate of $1 \mathrm{~mL} / \mathrm{min}$. A sharp peak was obtained for adefovir at a retention time of $3.55 \pm$ $0.01 \mathrm{~min}$. The method was validated according to the international guidelines. Linear regression analysis of data for the calibration plot showed a linear relationship between peak area and concentration over the range of $0.35-64 \mu \mathrm{g} / \mathrm{mL}$; the regression coefficient was 1 and the linear regression equation was $\mathrm{y}=42414 \mathrm{x}+5741$. The detection (LOD) and quantification (LOQ) limits were 5 and $15 \mathrm{ng} / \mathrm{mL}$, respectively.

\section{Ion-pair mediated octanol-buffer partitioning experiments \\ Ion-pairing theory}

The theory of formation of an ion-pair in an aqueous solution and its distribution in an immiscible organic solvent has been described by Miller et al. (10). Figure 2 illustrates the concept of ion-pair partitioning (22).

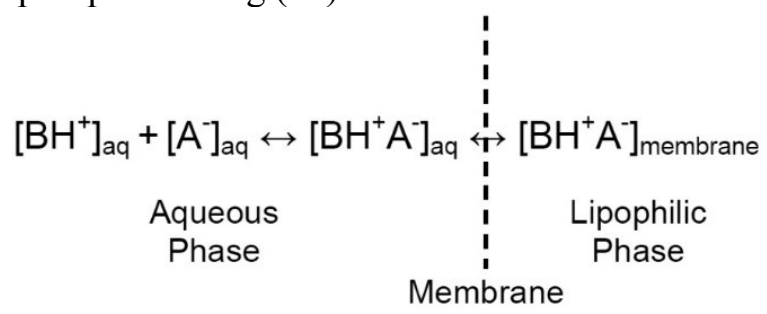

Figure 2. Ion-pair partitioning concept.

Briefly, assume that an acidic drug [A] interacts with a basic counter-ion [B]. The constant of formation of the ion-pair is described as (23):

$$
K_{11 a q}=\frac{\left[B H^{+} A^{-}\right]_{a q}}{\left[B H^{+}\right]_{a q}\left[A^{-}\right]_{a q}}
$$

in which $\left[A^{-}\right]_{\mathrm{aq}},\left[B H^{+}\right]_{\mathrm{aq}}$, and $\left[B H^{+} A^{-}\right]_{\text {aq }}$ are the aqueous phase concentrations of the acidic drug, the organic base and ion-pair, respectively. The intrinsic octanol-buffer partition coefficient of ionpair $\left[B H^{+} A^{-}\right]$can be described as:

$$
P_{A B}=\frac{\left[B H^{+} A^{-}\right]_{o c t}}{\left[B H^{+} A^{-}\right]_{a q}}
$$

Assuming the total amount of acidic drug in the octanol phase, $[\mathrm{At}]]_{\text {oct }}$ exists only as an ion-pair (i.e. $\left.[\mathrm{At}]_{\text {oct }} \approx\left[B \mathrm{BH}^{+} A^{-}\right]_{\mathrm{oct}}\right)$, the apparent octanol/buffer distribution coefficient $\mathrm{D}_{\mathrm{A}}=[\mathrm{At}]_{\text {oct }} /[\mathrm{At}]_{\mathrm{aq}}$, of the acidic drug can be expressed as:

$$
D_{A}=\frac{\left[B H^{+} A^{-}\right]_{o c t}}{[A]_{a q}+\left[B H^{+} A^{-}\right]_{a q}}
$$

By Combining of Equations (1), (2) and (3), the following equation is obtained:

$$
\frac{1}{D_{A}}=\frac{1}{K_{11 a q} P_{A B}[B]_{a q}}+\frac{1}{P_{A B}}
$$

Plotting $\frac{1}{D_{A}}$ versus $\frac{1}{[B]}$ produces a plot with a straight line. The Y-intercept is $\frac{1}{P_{A B}}$ and the line slope is $\frac{1}{K_{11 a q} P_{A B}}$, from which $K_{11 a q}$ and $P_{A B}$ can be estimated.

\section{Ion-pairing experimentation}

Octanol-buffer $(\mathrm{pH}=6.5)$ partitioning studies were performed using a method described elsewhere (20). Solutions of adefovir $(50 \mu \mathrm{g} / \mathrm{ml})$ were prepared in sodium phosphate buffer $(10 \mathrm{mM} ; \mathrm{pH}=$ 6.5) saturated with octanol at a molar excess of counter-ions. These aqueous solutions were then equilibrated at $30^{\circ} \mathrm{C}$ with an equivalent volume $(0.5$ $\mathrm{ml})$ of buffer-saturated octanol under magnetic stirring at $500 \mathrm{rpm}$ for $2.5 \mathrm{~h}$. Three replicates of each determination were carried out to assess reproducibility. The mixture was then centrifuged and the organic and aqueous phases were separated. The total drug concentration in the aqueous phase was then determined by HPLC. A solution depletion technique was employed for determination of the partition coefficient as:

$$
P=A_{0}-A_{\infty} A_{0}
$$


where $A_{0}$ is the initial concentration of the drug in the aqueous phase and $A_{\infty}$ is the final concentration of the drug in the aqueous phase after equilibrium has been established $(20,24-26)$.

\section{Parallel artificial membrane permeation assay (PAMPA)}

PAMPA is a valuable tool in the study of passive membrane permeation of drugs (27). PAMPA was performed using a method described elsewhere (20). A solution of adefovir with CPC (1:100 molar ratio) was prepared at a concentration of $0.2 \mathrm{mM}$ in $10 \mathrm{mM}$ sodium phosphate buffer $(\mathrm{pH}=6.5)$. Ninety-six-well multiscreen-IP filtration plates with PVDF filter support $(0.45 \mu \mathrm{m})$ were obtained from Merck Millipore (Ireland).

All filter support wells were impregnated with 5 $\mu 1$ of an artificial membrane solution (AMS) which consisted of lecithin in $n$-dodecane $(2 \% \mathrm{w} / \mathrm{v})$. Then, 10 min after the addition of AMS, the donor wells in three sets of matrices were loaded with appropriate solutions as follows: a $5 \times 3$ matrix of donor wells were each loaded with $150 \mu \mathrm{l}$ of the adefovir-counter-ion (CPC) solution and each acceptor well was loaded with $300 \mu$ of $10 \mathrm{mM}$ sodium phosphate buffer. This setting enabled collection of samples in triplicate at each time point of $30,60,90,120$ and $150 \mathrm{~min}$. Two other sets of $5 \times 3$ matrices were similarly loaded with adefovir solution $(0.8 \mathrm{mM})$ and ADV $(0.8 \mathrm{mM})$, respectively. The stacked donor-receiver plates then were incubated at $37^{\circ} \mathrm{C}$ in an orbital shaker rotating at $50 \mathrm{rpm}$. Samples were collected at each time point (at $30 \mathrm{~min}$ intervals over a $150 \mathrm{~min}$ time period) from each set of wells and the adefovir concentration in each well was assayed by HPLC. The apparent permeability coefficient $\left(\mathrm{P}_{\mathrm{app}} ; \mathrm{cm} / \mathrm{s}\right)$ was used to express artificial membrane permeability, which was calculated as (28):

$$
P_{a p p}=\frac{V r(d C r / d t)}{A C d}
$$

where $\mathrm{V}_{r}$ is the volume of the receiver compartment, $\mathrm{dC}_{\mathrm{r}}$ is the change in concentration of the receiver compartment, $\mathrm{d}_{\mathrm{t}}$ is the change in time, $A$ is the area of the filter membrane corrected for porosity, and $\mathrm{C}_{\mathrm{d}}$ is the concentration of the donor compartment at time zero. The filter membrane had a surface area of $0.32 \mathrm{~cm}^{2}$ and a porosity of $75 \%$; thus, the effective area of the filter membrane was calculated to be $0.24 \mathrm{~cm}^{2}$. A negative control permeability experiment was also performed, using enalaprilat (poorly permeable acidic compound) alone and in the presence of CPC to assess the effect of CPC concentration on the integrity of the PAMPA membrane.

\section{Everted gut sac assay}

Healthy male Wistar rats (240-270 g) purchased from the Pasteur Institute (Iran) were kept at a controlled temperature of $25^{\circ} \mathrm{C}$ with a $12: 12 \mathrm{~h}$ light:dark cycle. The rats only had access to water with no feeding on the night before the experiments. All protocols and procedures were approved by Shahid Beheshti University of Medical Sciences Ethics Committee for animal experiments (Tehran, Iran).

The everted sac technique was used as described by Wilson and Wiseman (29). Everted intestinal sacs were prepared by immediately removing the small intestine from fasted rats killed under $\mathrm{CO}_{2}$-anesthesia. The jejunum was excised, flushed through several times with saline solution at room temperature and placed quickly into oxygenated Krebs buffer solution at $37^{\circ} \mathrm{C}$. The intestine then was gently everted over a steel rod, filled with fresh oxygenated Krebs buffer solution and divided into sacs of approximately $4.5 \mathrm{~cm}$ in length with silk suture. The sacs were pre-incubated in oxygenated Krebs buffer solution at $37^{\circ} \mathrm{C}$ for 5 min and then placed in $25 \mathrm{ml}$ oxygenated Krebs buffer solutions at $37^{\circ} \mathrm{C}$ containing $20 \mu \mathrm{g} / \mathrm{ml}$ adefovir. Using these media, the transport of adefovir $(20 \mu \mathrm{g} / \mathrm{ml})$ in the absence (control) or presence of CPC (counter-ion) was measured. A similar set was prepared for ADV. Each set was replicated in triplicate. At the defined time points $(10,20,35,45,60,70$ and $90 \mathrm{~min})$ periodically for $90 \mathrm{~min}$, the sacs were removed and blotted dry. The sacs were cut open and the serosal fluid was drained into small Eppendorf vials and subjected to HPLC. The area of each sac was narrowly calculated. In order to accurately calculate the inner volume, each sac was weighed before and after fluid collection.

The apparent permeability coefficients $\left(\mathrm{P}_{\text {app}}\right.$; $\mathrm{cm} / \mathrm{s}$ ) were calculated according as:

$$
P_{a p p}=\frac{d Q}{d t} \cdot \frac{1}{A \cdot C_{0}}
$$

where $\frac{d Q}{d t}$ is the rate $(\mu \mathrm{g} / \mathrm{s})$ of total transport of the drug, $A$ is the surface area $\left(\mathrm{cm}^{2}\right)$ and $C_{0}$ is the initial 
donor concentration $(\mu \mathrm{g} / \mathrm{ml})$ (6). Possible cellular membrane damage was assessed by testing lactate dehydrogenase (LDH) release using an LDH kit (6) (LDH-P kit; Kimia Pajouhan; Iran).

\section{STATISTICAL ANALYSIS}

All values were expressed as mean \pm standard deviation (SD). Statistical differences were determined by ANOVA followed by Tukey's test for multiple comparisons at a significance level of $\mathrm{p}$ $<0.05$.

\section{RESULTS}

\section{Octanol-buffer partitioning of ion-pairs}

Adefovir exhibited a very small partition coefficient $\left(\mathrm{P}_{\mathrm{ow}}\right)$ of 0.014 . The apparent partition coefficient of adefovir in octanol/buffer was determined in the presence of anionic and cationic counter-ions. The lipophilicity and apparent partition coefficient of adefovir were not changed by the acidic anionic counter-ions (benzoic acid, succinic acid, citric acid and p-toluene sulfonic acid). These acids included alkyl and aromatic acids with one, two or three carboxylic groups or a sulfonic acid group.

The same set of experiments were performed over a wider $\mathrm{pH}$ range of 4 to 7 for the aqueous phase and no change in the lipophilicity of adefovir was observed; thus, ion-pairing as a basic part of the drug was ruled out.

Naphthyl amine, cyclohexyl amine and butyl amine were used as basic cationic counter-ions. These counter-ions were chosen based on their lipophilicity, chemical structure,flexibility and $\mathrm{pK}_{\mathrm{a}}$ values. No change in lipophilicity or the apparent partition coefficient of adefovir was observed in the presence of theses cationic counter-ions. Mixing adefovir with the quaternary ammonium compounds cetrimide and CPC was tested. The lipophilicity of adefovir increased up to 87-fold for cetrimide and up to 136-fold for CPC. Table 1 summarizes the $\mathrm{K}_{11 \mathrm{aq}}$ and $\mathrm{P}_{\mathrm{AB}}$ values for each adefovir ion-pair obtained using Equation (4). The double reciprocal plots of the apparent octanolbuffer partition coefficients of adefovir as a function of counter-ion concentration are shown in Figures 3 and 4 for adefovir-cetrimide and adefovirCPC.

Table 1. Summary of octanol-buffer partitioning of ion-pairs of adefovir $(\mathrm{n}=3)$. Data presented as mean $\pm \mathrm{SD}$. $\mathrm{P}<0.05$ versus adefovir.

\begin{tabular}{lll}
\hline Ion-pair & $\mathrm{K}_{11 \mathrm{aq}} \pm \mathrm{SD}$ & $\mathrm{P}_{\mathrm{AB}} \pm \mathrm{SD}$ \\
\hline Adefovir-Cetrimide & $12.99 \pm 2.22$ & $1.22 \pm 0.12$ \\
Adefovir-CPC & $9.99 \pm 1.92$ & $1.90 \pm 0.25$ \\
\hline
\end{tabular}

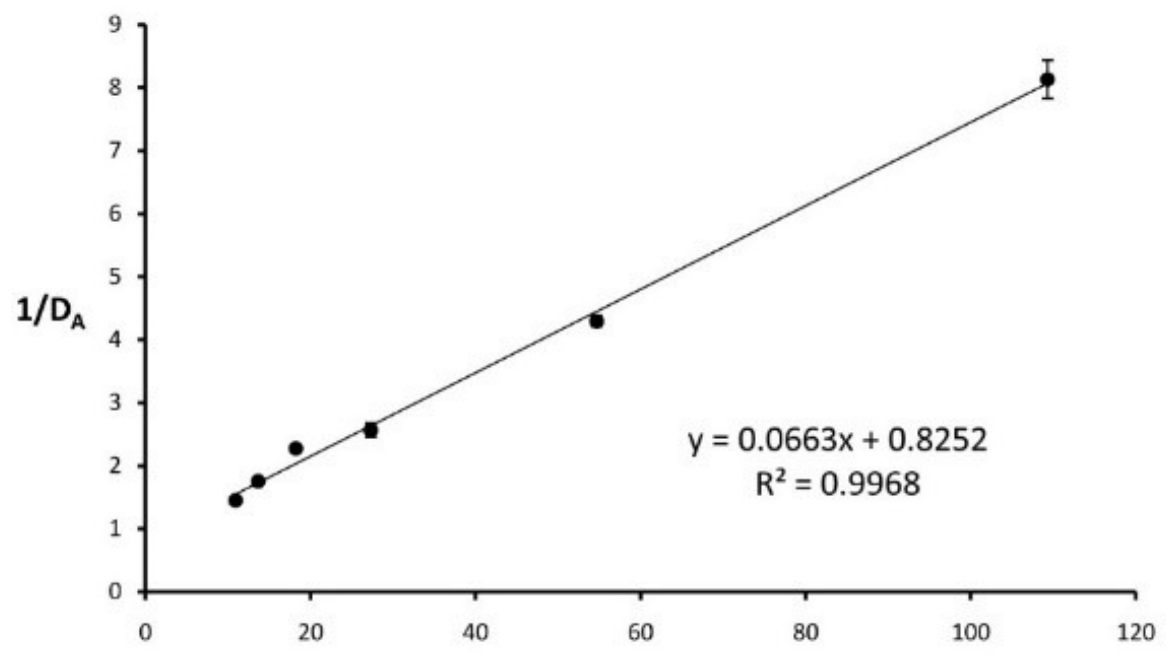

$1 /$ Cetrimide Concentration $\left(\mathrm{M}^{-1}\right)$

Figure 3. Double reciprocal plot of apparent octanol-buffer distribution coefficient of adefovir as a function of cetrimide concentration, $\left(\mathrm{C}_{0}=50 \mu \mathrm{g} / \mathrm{ml} ; \mathrm{n}=3\right)$. The results are expressed as mean $\pm \mathrm{SD}$. 




Figure 4. Double reciprocal plot of apparent octanol-buffer distribution coefficient of adefovir as a function of CPC concentration, $\left(\mathrm{C}_{0}=50 \mu \mathrm{g} / \mathrm{mL} ; \mathrm{n}=3\right)$. The results are expressed as mean $\pm \mathrm{SD}$.

Ion-pair mediated transport in PAMPA model A PAMPA model consisting of lecithin/n-dodecane $(2 \% \mathrm{w} / \mathrm{v})$ was used as a hydrophobic liquid membrane and transportation of the ion-pairs assessed in it. Adefovir alone showed negligible absorption through this membrane. The increase in adefovir apparent permeability in the presence of CPC (counter-ion) in the PAMPA model is shown

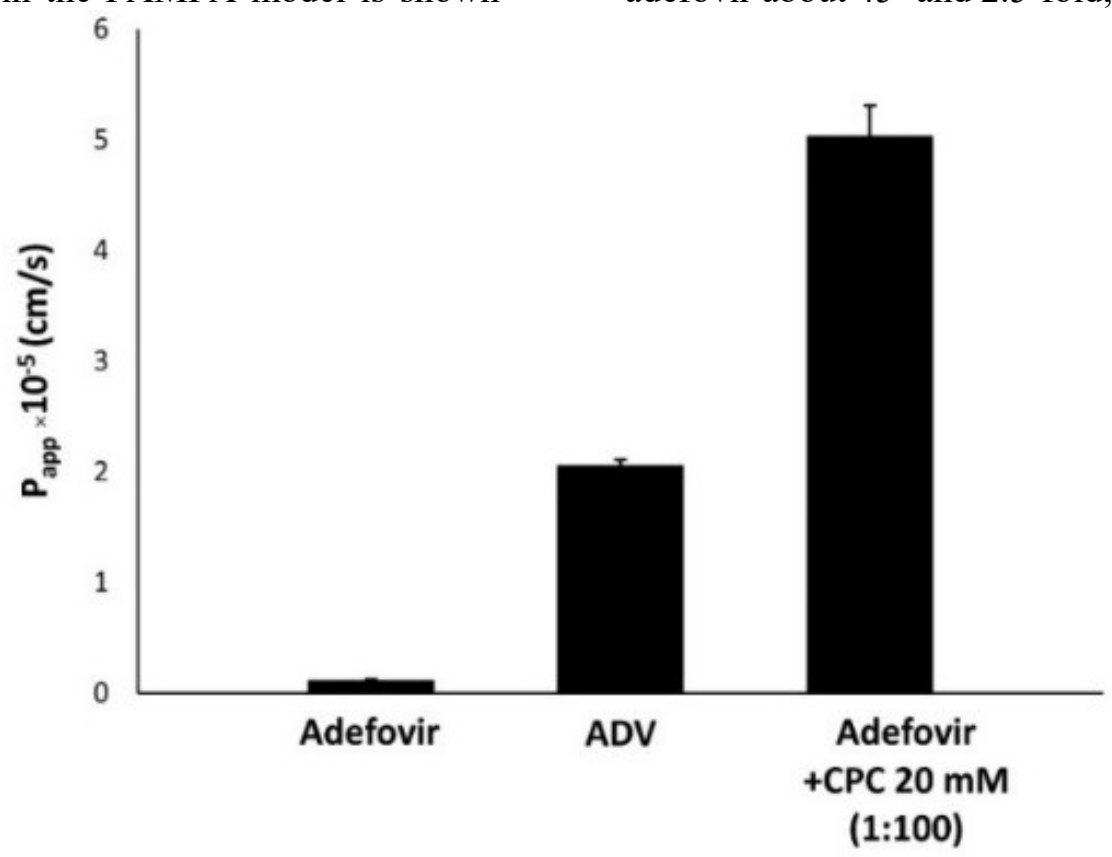

\section{(1:100)}

in Figure 5. The mass transport of the drug over time is shown in Figure 6. Table 2 summarizes the permeability values obtained in the PAMPA studies for adefovir-CPC, adefovir, ADV and enalaprilat (negative control). Compared to the adefovir base and ADV, the presence of CPC substantially increased the PAMPA apparent permeability of adefovir about 45- and 2.5-fold, respectively.

Figure 5. . Apparent permeability $\left(\mathrm{P}_{\text {app }} ; \mathrm{cm} / \mathrm{s} \times 10^{-5}\right)$ of adefovir, ADV and adefovir + CPC $20 \mathrm{mM}(1: 100$ molar ratio $)$ in PAMPA model $(\mathrm{n}=3)$. Data presented as mean $\pm \mathrm{SD}$. $\mathrm{P}<0.01$ versus to ADV and adefovir. (Significant level is $\mathrm{P}<0.05$ ). 


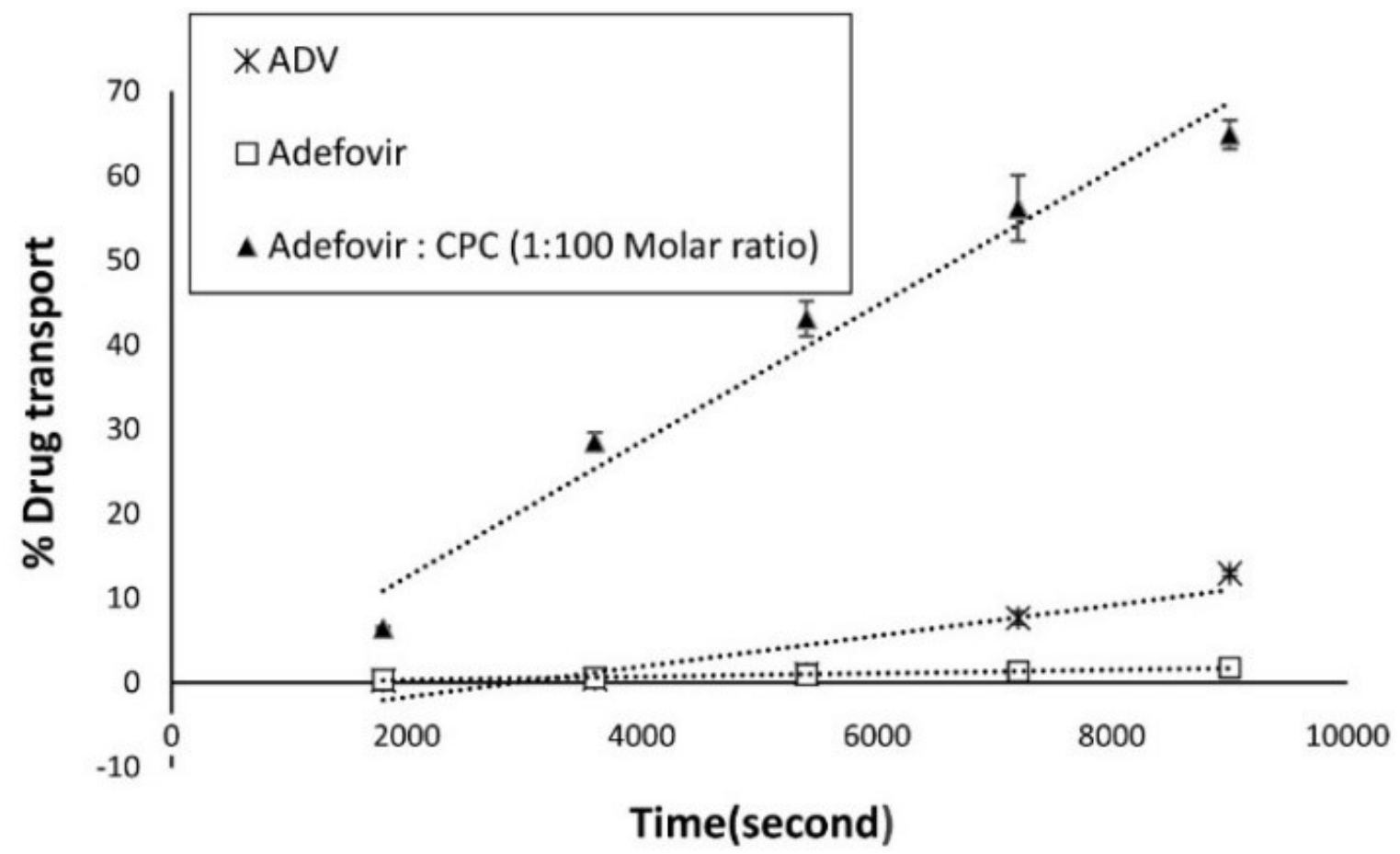

Figure 6.. Drug transport percentage of adefovir, ADV and adefovir + CPC $20 \mathrm{mM}(1: 100$ molar ratio) in PAMPA model $(\mathrm{n}=3)$. The results are expressed as mean $\pm \mathrm{SD}$. $\mathrm{P}<0.01$ versus to $\mathrm{ADV}$ and adefovir. (Significant level is $\mathrm{P}<0.05$ ).

Table 2. Apparent permeability ( $\left.\mathrm{P}_{\text {app }}\right)$ of adefovir, ADV, adefovir + CPC $20 \mathrm{mM}$ (1:100 molar ratio) and enalaprilat (negative control) in PAMPA model $(\mathrm{n}=3$ ). Data presented as mean $\pm \mathrm{SD} . \mathrm{P}<0.01$ versus ADV and adefovir. (Significant level is $\mathrm{P}<0.05$ )

\begin{tabular}{lccl}
\hline Compound & Concentration $(\mathrm{mM})$ & CPC Concentration $(\mathrm{mM})$ & $\mathrm{P}_{\text {app }} \pm \mathrm{SD}\left(10^{-5} \mathrm{~cm} / \mathrm{s}\right)$ \\
\hline Adefovir & 0.8 & 0 & $0.1127 \pm 0.0013$ \\
Adefovir & 0.2 & 20 & $5.03 \pm 0.282$ \\
ADV & 0.8 & 0 & $2.053 \pm 0.056$ \\
Enalaprilat & 0.2 & 20 & $<0.001$ \\
Enalaprilat & 0.2 & 0 & $<0.001$ \\
\hline
\end{tabular}

\section{Ion-pair mediated transport across everted gut sac model}

In order to confirm the results obtained using PAMPA model, the ability of CPC to facilitate intestinal permeation of adefovir through ion-pair formation was evaluated in an everted rat gut sac assay. Figure 7 shows the influence of CPC on the permeation of adefovir into everted rat gut sac compared to the permeability of adefovir and ADV without CPC. An increase in adefovir apparent permeability $\left(\mathrm{P}_{\text {app }}\right)$ was observed in the presence of $3.5 \mathrm{mM}$ CPC (1:50 molar ratio). The everted gut sac $\mathrm{P}_{\text {app }}$ values for the adefovir-CPC ion-pairs, adefovir and ADV are presented in Table 3. Figure 8 clearly shows that the integrity of the intestinal mucosal membrane was unchanged and that mass transport was linear over time. The apparent permeability of adefovir increased 2-fold in the presence of $3.5 \mathrm{mM} \mathrm{CPC}$ and there were statistically significant differences between adefovir permeability and that of adefovir with CPC. Furthermore, the permeability of adefovir in the presence of CPC was 1.3-fold greater than that of ADV. Statistically, there was a significant difference between the permeability of adefovir$\mathrm{CPC}$ and $\mathrm{ADV}$. 


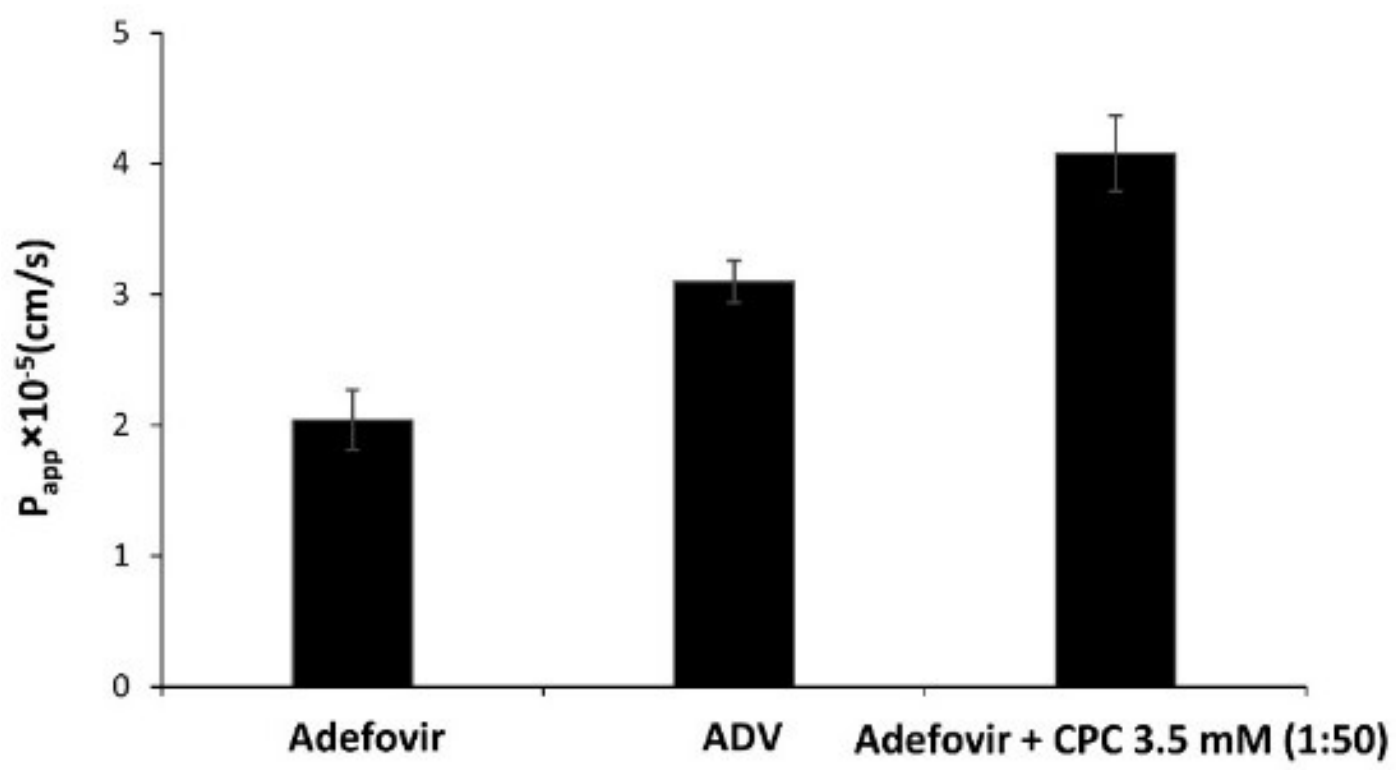

Figure 7. Apparent permeability $\left(\mathrm{P}_{\mathrm{app}} ; \mathrm{cm} / \mathrm{s} \times 10^{-5}\right)$ of adefovir, ADV and adefovir $+\mathrm{CPC} 3.5 \mathrm{mM}(1: 50 \mathrm{molar}$ ratio) using everted gut sacs $\left(\mathrm{C}_{0}=20 \mu \mathrm{g} / \mathrm{ml} ; \mathrm{n}=3\right.$ rats). The results are expressed as mean $\pm \mathrm{SD} . \mathrm{P}<0.05$ versus $\mathrm{ADV}, \mathrm{P}<0.01$ versus adefovir (Significant level is $\mathrm{P}<0.05$ ).

Table 3. Apparent permeability $\left(\mathrm{P}_{\text {app }}\right)$ of adefovir, ADV and adefovir + CPC $3.5 \mathrm{mM}(1: 50$ molar ratio) using everted gut sacs $(\mathrm{n}=3$ rats). Data presented as mean $\pm \mathrm{SD}$. $\mathrm{P}<0.05$ versus $\mathrm{ADV}, \mathrm{P}<0.01$ versus adefovir (Significant level is $\mathrm{P}<0.05$ ).

\begin{tabular}{ll}
\hline Compound & $\mathrm{P}_{\text {app }} \pm \mathrm{SD}\left(10^{-5} \mathrm{~cm} / \mathrm{s}\right)$ \\
\hline Adefovir & $2.04 \pm 0.23$ \\
ADV & $3.10 \pm 0.16$ \\
Adefovir + CPC 3.5 & $4.08 \pm 0.29$ \\
mM (1:50) & \\
\hline
\end{tabular}

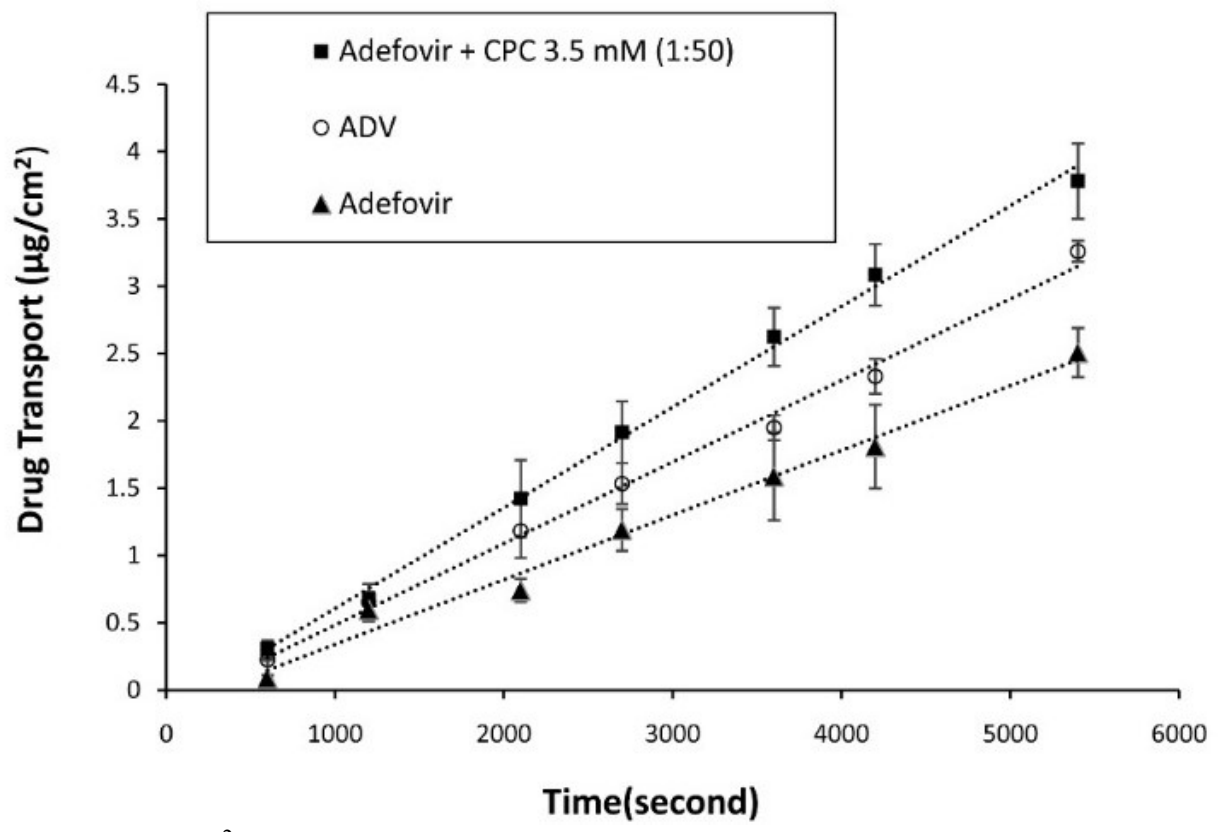

Figure 8. Permeation rate $\left(\mu \mathrm{g} / \mathrm{cm}^{2}\right)$ of adefovir, ADV and adefovir $+\mathrm{CPC} 3.5 \mathrm{mM}(1: 50$ molar ratio) using everted gut sacs $\left(\mathrm{C}_{0}=20 \mu \mathrm{g} / \mathrm{ml} ; \mathrm{n}=3\right.$ rats $)$. The results are expressed as mean $\pm \mathrm{SD} . \mathrm{P}<0.05$ versus $\mathrm{ADV}, \mathrm{P}<0.01$ versus adefovir (Significant level is $\mathrm{P}<0.05$ ). 


\section{DISSCUSION}

Adefovir is a highly polar, thus, hydrophilic compound, with insufficient intestinal permeability is (5). The $\mathrm{pKa}$ values of adefovir are 4.2 and 9.8 (attributed to basic adenine functionality) and 2 and 6.8 (attributed to phosphate moiety) $(30,31)$. In order to improve adefovir lipophilicity and permeation through artificial and biological membranes by ion-pairing both functionalities, the basic adenine and acidic phosphate groups were considered. Adenine at a low-to-medium $\mathrm{pH}$ buffer is protonated and undergoes amine-imino tautomeric rearrangement which stabilizes the positive charge (32) and reduces its tendency to form ion-pairs with acidic counter ions. Increasing the molar concentration of the acidic counter-ions had no effect on the lipophilicity and apparent partition coefficient of the drug; thus, ion pairing as the basis of the drug was ruled out. Attention then was focused on the acidic phosphate groups of adefovir (deprotonation of phosphate groups leads to anion formation). Cationic counter-ions also were not effective.

Cetrimide and CPC (quaternary ammonium salts) showed substantially increased lipophilicity compared to the free drug (up to 87-fold for cetrimide and 136-fold for CPC). It appears that in addition to the interaction of the acidic moieties with quaternary amine of cetrimide and $\mathrm{CPC}$, long hydrocarbon chains of the two cations increased the lipophilicity of the complexes. The higher lipophilicity of CPC could be attributed to the pyridine ring of the compound, which is more lipophilic than the three methyl groups of cetrimide. The results from the octanol-buffer $(\mathrm{pH}$ 6.5) partitioning of the ion-pairs (Table 1) showed that the adefovir-CPC ion-pair $\left(\mathrm{P}_{\mathrm{AB}}=1.9\right)$ was 1.5 orders of magnitude more lipophilic than the adefovir-cetrimide ion-pair $\left(\mathrm{P}_{\mathrm{AB}}=1.22\right)$. Conversely, the $\mathrm{K}_{11 \text { aq }}$ of the adefovir-cetrimide was 1.5 orders of magnitude higher than that of the adefovir-CPC ion-pair (12.99 versus $\left.9.99 \mathrm{M}^{-1}\right)$, indicating a much stronger intermolecular complex for the adefovir-cetrimide ion-pair. As shown in Figures 3 and 4, the double reciprocal plots for both ion-pair systems gave highly linear results $\left(\mathrm{R}^{2}>\right.$ 0.99), indicating excellent agreement with Equation (4). These plots confirm the formation of ion-pairs between adefovir-cetrimide and adefovir-CPC and that the distribution coefficient of adefovir increased depending on the molar concentration of the counter-ions.

As shown in Figure 6, ion-pairing was an effective method to enhance the permeation of adefovir in PAMPA in the presence of CPC (counter-ion); thus, the permeability of adefovir increased to above that of ADV. The linearity of the mass transport of drug over time indicated that the lipid membrane integrity was satisfactory (Figure 6) and the increase in adefovir permeability in the presence of CPC was not caused by lipid membrane defection. No measurable permeability was observed for the negative control compound, enalaprilat, either alone or in the presence of CPC. This indicates that the increase in adefovir permeability was not due to a decrease in the PAMPA membrane integrity by CPC, which is supporting evidence for ion-pairing formation (Table 3). Everted gut sacs as a biologic membrane model confirmed the results of the octanol-buffer ( $\mathrm{pH}$ 6.5) partitioning study and the artificial membrane (PAMPA) and permeability of the adefovir in the presence of CPC increased 1.3-fold over that of ADV. These results indicate that ionpairing could be considered as an alternative to the prodrug (ADV). As the intestine membrane is viable and integrant, and the transporters and enzymes present in everted gut sac technique and this method is high reproducible and reliable (33), we can expect the similar results in intact animal or humans. The study of Mrestani et al. (25) and Park et al. (34) supported our results. Mrestani et al. improved lipophilicity and membrane transport of cefuroxime using intestinal membrane model through ion-pair formation with four quaternary ammonium salts like cetylpyridinium chloride. Park et al. improved the nasal and intestinal resorption of cefotaxime through ion-pair formation with cetylpyridinium chloride.

\section{CONCLUSION}

The influence of counter-ions on the partitioning of adefovir into octanol and its transport across the PAMPA membrane and everted gut sacs was investigated. Ion-pair formation between adefovir and CPC strongly influenced the permeation across the membranes. Tolerated concentrations of CPC for both transport models were applied. The results demonstrate that ion-pairing can be a valuable tool for enhancing lipophilicity and permeability across biological membranes of ionic drugs such as 
adefovir. Adefovir can be suggested as a simple formulation in combination with CPC to improve permeation as a substitute to the prodrug adefovir dipivoxil.

\section{ACKNOWLEDGMENT}

This study is part of the $\mathrm{PhD}$ thesis of Bahar Darsazan, proposed and approved by the School of Pharmacy at Shahid Beheshti University of Medical Sciences (SBMU) in Tehran, Iran. The authors would also like to thank the research deputy of SBMU for providing the financial support to conduct this research.

\section{REFRENCES}

1. Marcellin P, Chanq TT, Lim SG, Tonq MJ, SievertW, Shiffman Ml, et al. Adefovir dipivoxil for the treatment of hepatitis $\mathrm{B}$ e antigen-positive chronic hepatitis B. N Engl J Med, 2003; 348 (9): 808-816.

2. Manolakopoulos S, Bethanis S, Koutsounas S, Goulis J, Vlachogiannakos J, Christias E, et al. Long-term therapy with adefovir dipivoxil in hepatitis B e antigen-negative patients developing resistance to lamivudine. Aliment Pharmacol Ther, 2008; 27 (3): 266-273.

3. ADHOC International Steering Committee. A randomized placebo-controlled trial of adefovir dipivoxil in adefovir dipivoxilanced HIV infection: The ADHOC trial. HIV Med, 2002; 3(4): 229-238.

4. Danta M, Dusheiko G. Adefovir: review of a novel acyclic nucleoside analogue. Int J Clin Pract, 2004; 58(9): 877-886.

5. Cundy KC, Sue IL, Visor GC, Marshburn J, Nakamura C, Lee WA, et al. Oral formulation of adefovir dipivoxil: in vitro dissolution and in vivo bioavailability in dogs. J Pharm Sci, 1997; 86(12): 1334-1338.

6. Li P, Yu H, Zhang XX, Gan L, Zhu CL, Gan Y, et al. Absorption enhancement of adefovir dipivoxil by incorporating MCT and ethyl oleat complex oil phase in emulsion. Acta Pharmacol Sin, 2010; 31(7): 881-888.

7. Abla N, Chinn LW, Nakamura T, Liu L, Huang CC, Johns SJ. Et al. The human multidrug resistance protein 4 (MRP4, ABCC4): functional analysis of a highly polymorphic gene. J Pharmacol Exp Ther 2008; 325(3): 859-868.

8. Ming $\mathrm{X}$, Thakker DR. Role of basolateral efflux transporter MRP4 in the intestinal absorption of the antiviral drug adefovir dipivoxil. Biochem Pharmacol 2010; 79(3): 455-462.
9. Gomez-Orellana I. Strategies to improve oral drug bioavailability. Expert Opin Drug Deliv, 2005; 2(3): 419-433.

10. Miller JM, Dahan A, Gupta D, Varghese S,Amidon GL, et al. Quasi-equilibrium analysis of the ion-pair mediated membrane transport of low-permeability drugs. J Control Release, 2009; 137(1): 31-37.

11. Suresh PK, Paul SD. Ion-paired drug delivery: an avenue for bioavailability improvement. J Biomed Res, 2011, 3(2): 70-76.

12. Neubert R. Ion-pair transport across membranes. Pharm Res, 1989; 6: 743-747.

13. Neubert R, Fischer S. Influence of lipophilic counter-ions on the transport of ionizable hydrophilic drugs. J Pharm Pharmacol, 1991; 43:204-206.

14. Mrestani Y, Hartl A, Neubert RHH. Influence of absorption enhancers on the pharmacokinetic properties of non-oral $\beta$-lactam-cefpirom using the rabbit (chinchilla) in vivo model. Int J Pharm, 2006; 309:67-70.

15. Roos BP, DeCruz SE, Lynch TB, Davis-Goff K, Toth I, et al. Design, synthesis, and evaluation of a liposaccharide drug delivery agent: application to the gastrointestinal absorption of gentamicin. J Med Chem, 2004; 47: 1251-1258.

16. Dal Pozzo A, Acquasaliente M, Geron MR. New heparin complexes active by intestinal absorption: 1multiple ion pairs with basic organic compounds. Thromb Res, 1989; 56: 119-124.

17. Gibaldi M, Grundhofer B. Enhancement of intestinal absorption of a quaternary ammonium compound by salicylate and trichloroacetate. J Pharm Sci, 1973; 62:343-344.

18. Walking WD, Holmes DG, Cressman WA, Dix RK, Piperno E, Mosher AH. Possible ion-pair mediated absorption of mixidine ll: plasma levels and histology. J Pharm Sci, 1978; 67: 948-950.

19. Irwin GM, Kostenbauder HB, Dittert LW, Staples R, Misher A, Swintosky JV. Enhancement of gastrointestinal absorption of a quaternary ammonium compound by trichloroacetate. J Pharm Sci, 1969; 58: 313-315.

20. Samiei N, Shafaati A, Zarghi A, Moghimi HR, Foroutan SM. Enhancement and in vitro evaluation of amifostine permeation through artificial membrane (PAMPA) via ion-pairing approach and mechanistic selection of its optimal counter-ion. Eur J Pharm Sci, 2014; 23(51):218-223.

21. Darsazan B, Shafaati A, Mortazavi SA, Zarghi A. A Simple and Specific Stability- Indicating RP-HPLC Method for Routine Assay of Adefovi Dipivoxil in Bulk and Tablet Dosage Form. Iran J Pharm Res, 2017; 16(1): 132-139.

22. Grant DJW, Higuchi T. Ion-pairs and solubility Behavior. In: Weissberger A, editor. Solubility 
Behavior of organic compounds. New York: John Wiley \& Sons; 1990. p. 399-433.

23. Connors KA. Binding Constants: The Measurement of Molecular Complex Stability. New York (NY): John Wiley \& Sons; 1987.

24. Ivaturi VD, Kim SK. Enhanced permeation of methotrexate in vitro by ion-pair formation with Larginine. J Pharm Sci, 2009; 98: 3633-3639.

25. Mrestani Y, Mrestani-Klaus C, Bretschneider B, Neubert RH. Improvement of lipophilicity and membrane transport of cefuroxime using in vitro models. Eur J Pharm Biopharm, 2004; 58: 653-657.

26. Zhu C, Jiang L, Chen TM, hwang KK. A comparative study of artificial membrane permeability assay for high throughput profiling of drug absorption potential. Eur J Med Chem, 2002; 37: 399-407.

27. kansy M, Senner F, Gubernator K. Physicochemical high throughput screening: parallel artificial membrane permeation assay in the description of passive absorption processes. J Med Chem, 1998; 41(7): 1007-1010.
28. Seo PR, Teksin ZS, Kao JP, Polli JE. Lipid composition effect on permeability across PAMPA. Eur J Pharm Sci, 2006; 29(3-4):259-268.

29. Wilson TH, Wiseman G. The use of sacs of everted small intestine for the study of the transference of substances from the mucosal to the serosal surface. $\mathrm{J}$ Physiol, 1954; 123: 116-125.

30. Dawson R M C, Elliott DC, Elliott WH, Jones KM, editors. Data for Biochemical Research. 3rd ed. Oxford: Clarendon Press; 1959.

31. Rautio J, editor. Prodrugs and Targeted Delivery: Towards Better ADME Properties. 47th ed. Weinheim: WILEY-VCH Verlag \& CO; 2011.

32. Pullman B, Berthod H, Dreyfus M. Amine-imine tautomerism in adenines. Theoret chim Acta, 1969; 15(3): 265-268.

33. Barthe L, Woodley J, Houin G. Gastrointestinal absorption of drugs: methods and studies. Fundam Clin Pharmacol 1999; 13(2): 154-68.

34. Park GB, Jeon S, Lee K-P. [Effect of ion-pair on jejunal and nasal absorption of cefotaxime]. J Kor Pharm Sci 1995; 25(4): 353-63 [in Korean]. 